\title{
PERBEDAAN PENGARUH MEDIA LEMBAR BALIK DAN KARTU KENDALI EDUKASI TERHADAP PENGETAHUAN DAN SIKAP IBU MENYUSUI TENTANG ASI EKSKLUSIF DI WILAYAH KERJA PUSKESMAS KOPPE KABUPATEN BONE
}

\author{
*Sutriani', Muhammad Khidri Alwi ${ }^{1,}$ Andi Asrina ${ }^{1}$ \\ 'Program Pascasarjana Kesehatan Masyarakat, Universitas Muslim Indonesia
}

*Email: Sutriani.genda20@gmail.com

\begin{abstract}
ABSTRAK
Latar Belakang: Cakupan ASI Eksklusif masih banyak yang tidak mencapi target dan masih banyak ibu yang tidak memberikan ASI Eksklusif kepada bayinya karena minimnya pengetahuan mengenai manfaat ASI Eksklusif dan sikap atau kebiasaan yang dilakukan tanpa melalui penalaran apakah yang dilakukannya baik atau tidak dalam pemberian ASI. Tujuan penelitian ini adalah untuk menganalisis perbedaan pengaruh media lembar balik dan kartu kendali edukasi terhadap pengetahuan dan sikap ibu menyusui tentang ASI Eksklusif di wilayah kerja puskesmas Koppe Kabupaten Bone. Metode: Desain penelitian yang digunakan adalah Quasi experiment dengan rancangan two group pretest dan posttest design. Tehnik pengambilan sampel dalam penelitian ini adalah purposive sampling yaitu sebanyak 70 responden. Analisis data menggunakan uji statistic Paired Samples Test dan independent $t$-test dengan tingkat kemaknaan $95 \%(\alpha$ : 0,05). Hasil: Hasil penelitian pada dua kelompok intervensi menggunakan uji Paired Samples Test menunjukkan ada pengaruh pengetahuan dan sikap ibu menyusui tentang ASI Eksklusif sebelum dan sesudah penggunaan media lembar balik dan kartu kendali edukasi dengan $\mathrm{p}$ value masing-masing 0,000 ( $\mathrm{p}$ value $<0,05$ ). Ada perbedaan pengaruh pengetahuan antara kelompok lembar balik dan kartu kendali edukasi setelah diberikan intervensi dengan menggunakan uji independent t-tes ( $\mathrm{p}$ value $0.002<0,05$ ). Tidak ada perbedaan pengaruh sikap antara kelompok lembar balik dan kartu kendali edukasi setelah diberikan intervensi ( $\mathrm{p}$ value $0.085>0,05$ ). Kesimpulan: Terdapat pengaruh penggunaan media lembar balik dan kartu kendali edukasi terhadap pengetahuan dan sikap ibu menyusui tentang ASI Eksklusif. Terdapat perbedaan pengaruh pengetahuan antara kelompok lembar balik dan kartu kendali edukasi setelah diberikan intervensi dan tidak ada perbedaan pengaruh sikap antara kelompok lembar balik dan kartu kendali edukasi setelah diberikan intervensi.
\end{abstract}

Kata kunci: Lembar Balik, Kartu Kendali, Pengetahuan, Sikap, ASI Eksklusif 


\begin{abstract}
Background: There are still many exclusive breastfeeding coverage that do not reach the target and there are still many mothers who do not give exclusive breastfeeding to their babies because of the lack of knowledge about the benefits of exclusive breastfeeding and their attitudes or habits without reasoning whether they are doing well or not in breastfeeding. The purpose of this study was to analyze the differences in the influence of flipchart media and educational control cards on the knowledge and attitudes of breastfeeding mothers about exclusive breastfeeding in the working area of the Koppe Community Health Center, Bone Regency. Methods: The research design used was a quasi experiment with two group pretest and posttest designs. The sampling technique in this study was purposive sampling as many as 70 respondents. Data analysis used the Paired Samples Test statistical test and independent t-test with a significance level of 95\% ( $\alpha: 0.05)$. Results: The results of the study in the two intervention groups using the Paired Samples Test showed that there was an influence on the knowledge and attitudes of breastfeeding mothers about exclusive breastfeeding before and after using flipchart media and educational control cards with each $\mathrm{p}$ value of 0.000 ( $\mathrm{p}$ value <0.05). There was a difference in the effect of knowledge between the flipchart group and the educational control card after being given the intervention using the independent $t$-test ( $p$ value $0.002<0.05$ ). There was no difference in the effect of attitudes between the flipchart group and the educational control card after being given the intervention ( $\mathrm{p}$ value 0.085> 0.05). Conclusion: There is an effect of using flipchart media and educational control cards on the knowledge and attitudes of breastfeeding mothers about exclusive breastfeeding. There was a difference in the influence of knowledge between the flipchart group and the educational control card after the intervention was given and there was no difference in the effect of attitudes between the flipchart group and the education control card after the intervention was given.

Keywords: Flipchart, Control Card, Knowledge, Attitude, Exclusive Breastfeeding

\section{LATAR BELAKANG}

World Health Organization (WHO) melaporkan bahwa pada tahun 2017 angka inisiasi menyusu dini (IMD) $51 \%$ per 1000 kelahiran. Tahun 2018 inisiasi menyusu dini (IMD) mengalami kenaikan yaitu $60 \%$ per 1000 kelahiran dari hasil yang ingin dicapai $100 \%$. Dalam tahun 2019 diharapkan sudah mampu mencapai angka 100\% atau setidaknya mendekati target. Sedangkan ASI Eksklusif tahun 2017 dilaporkan

terdapat 1300 bayi usia 0-6 bulan dan terdapat 1000 bayi yang tidak mendapatkan ASI Eksklusif. Hal ini diperparah dengan meningkatnya presentase pemberian susu formula dibandingkan ASI Eksklusif pada tahun 2018 yaitu terdapat 1600 bayi usia 0-6 bulan dan Hubungan Pelaksanaan IMD dan Pemberian Asi Eksklusif. (1)

Faktor yang mempengaruhi rendahnya pemberian ASI Eksklusif antara lain pengetahuan tentang pentingnya ASI Eksklusif masih rendah.
\end{abstract}


Pengetahuan ibu yang berkaitan dengan ASI Eksklusif ini sebenarnya sudah harus di mulai ketika ibu masih dalam keadaan hamil, sehingga ibu dapat mempersiapkan pemberian ASI secara eksklusif dengan baik dan benar.

Ketidaktahuan ibu tentang keunggulan ASI dapat memberi pengaruh buruk pada bayi. Apabila bayi tidak mendapatkan ASI dengan baik, bayi tidak akan mendapatkan zat gizi yang baik dalam ASI. Pengetahuan ibu yang baik pula maka pemberian ASI Eksklusif pada balita juga akan meningkat Pengetahuan atau kognitif merupakan faktor domain yang sangat penting untuk terbentuknya sikap dan tindakan seseorang (Over Behavior), sikap dan perilaku yang didasari oleh pengetahuan akan lebih langgeng dari pada sikap dan perilaku yang tidak didasari oleh pengetahuan, sebelum orang mengadopsi sikap dan perilaku baru (berperilaku baru) didalam diri seseorang. (2)

Hasil penelitian (Prasetio, Permana, \& Sutisna, 2020) tentang Hubungan Pengetahuan, Sikap, dan Perilaku Ibu Tentang ASI dengan Keberhasilan ASI Eksklusif : Puskesmas Pancalang Kabupaten Kuningan. Menunjukkan terdapat hubungan yang bermakna antara tingkat pengetahuan dengan keberhasilan ASI Ekslusif karena dari 93 responden dengan tingkat pengetahuan terbanyak yaitu pada tingkat pengetahuan baik sebanyak 61 responden (65.6\%). Sedangkan untuk responden dengan tingkat pengetahuan kurang yaitu sebanyak 32 responden (34.4\%). Tingkat pengetahuan yang tinggi dapat mempengaruhi pula pola pikir seseorang atau bahkan masyarakat dari yang negatif menjadi positif karena hal itu di dasari oleh kesadaran, rasa tertarik, dan adanya pertimbangan sikap positif. (3)

Salah satu upaya untuk meningkatkan cakupan pemberian ASI Eksklusif adalah dengan promosi kesehatan. Promosi kesehatan tidak hanya menyadarkan masyarakat atau meningkatkan pengetahuan masyarakat tentang kesehatan tetapi terdapat usaha untuk memfasilitasinya dengan tujuan perubahan perilaku masyarakat. Berkaitan dengan edukasi, khususnya untuk peningkatan pengetahuan dan sikap ibu mengenai ASI Eksklusif, diperlukan media sebagai alat bantu untuk meningkatkan pengetahuan dan keterampilan untuk tenaga kesehatan dan masyarakat, seperti diketahui bahwa alat peraga akan sangat membantu di dalam promosi kesehatan agar pesan-pesan kesehatan dapat disampaikan lebih jelas kepada masyarakat sehingga sesuai sasaran dan masyarakat dapat menerima pesan tersebut dengan jelas dan tepat pula. Media komunikasi yang baik mampu 
memberikan informasi yang mudah diterima dan mudah diingat oleh ibu, sehingga dapat mendorong keinginan ibu untuk mengetahui dan mendapatkan pemahaman yang lebih baik. (4)

Hasil penelitian (Muldaniyah, Ahmad, \& Hadju, 2019) tentang Efek Kartu Kendali Edukasi Inisiasi Menyusu Dini pada Ibu Hamil Trimester III Ada pengaruh kartu kendali edukasi dalam meningkatkan pengetahuan ibu hamil tentang IMD dengan $\mathrm{p}=0,000$ yaitu pengetahuan kurang sebelum edukasi 40,5, setelah pemberian edukasi pertama menggunakan kartu pengetahuan ibu meningkat menjadi 50,17, pada edukasi edukasi ke dua menjadi 60,17 dan pada edukasi terakhir menjadi 73,17 Hal ini membuktikan bahwa kartu kendali edukasi dapat meningkatkan pengetahuan ibu hamil akan praktik IMD secara signifikan. (5)

Berdasarkan data Riset Kesehatan Dasar (Riskesdas) Tahun 2017, presentase tertinggi proses mulai menyusui pada anak 0-23 bulan adalah pada 1-6 jam $(35,2 \%)$. Proses mulai menyusu pada 1 jam pertama setelah lahir/IMD hanya $34,5 \%$. IMD mengalami peningkatan pada tahun 2018, proporsi IMD pada anak umur 0-23 bulan adalah 1-6 jam (49,5\%). Di tahun 2019 ini pemerintah menargetkan bisa $100 \%$ anak yang mendapatkan ASI Eksklusif dan IMD dengan adanya peraturan daerah tentang ASI Eksklusif dan IMD. tahun 20162018, menunjukkan bahwa ibu-ibu yang memberikan ASI Eksklusif pada bayi di bawah usia dua bulan cukup banyak (64\% dari total bayi yang ada). Namun, persentase tersebut menurun seiring dengan bertambahnya usia bayi. Yaitu, hanya $46 \%$ pada bayi usia 2-3 bulan dan $14 \%$ pada bayi usia $4-5$ bulan. Selain itu, satu dari tiga bayi usia 2-3 bulan telah diberi makanan tambahan. (6)

Dinas Kesehatan Provinsi Sulawesi Selatan melaporkan bahwa pada Tahun 2016 terdapat 800 bayi dengan usia 0-6 bulan, terdapat $400(50,00 \%)$ bayi yang tidak mendapatkan ASI Eksklusif pada bulan ke 3 dan ke 4. Pada tahun 2017 terdapat 750 bayi usia 0-6 bulan, tercatat $340(45,33 \%)$ bayi yang tidak mendapatkan ASI Eksklusif pada bulan ke 4 dan ke 5. Sedangkan pada tahun 2018 terdapat 800 bayi usia 0-6 bulan, terdapat $250 \quad(31,25 \%)$ bayi yang tidak mendapatkan ASI Eksklusif. (7)

Media cetak seperti leaflet, booklet, flipchart (lembar balik), poster. Flipchart (lembaran balik) akan memudahkan pekerjaan untuk menerangkan dan memberikan informasi dengan gambar tahap demi tahap. Setiap tahapan memiliki satu gambar yang bernomor setelah selesai maka lembaran gambar tersebut dibalikan begitu 
seterusnya hingga akhir. Kelebihan lembar balik adalah gambar yang jelas dan dapat dilihat secara bersama-sama, menarik dan mudah dimengerti. (8)

Menurut (Ahmad 2017) mengemukan bahwa jenis media visual buku saku menunjukan angka 75\%-100\% dikatagorikan layak sebagai media promosi kesehatan jika buku saku dikemas secara lengkap, berisikan materi menarik, bisa dibawa dan dapat dimanfaatkan kapanpun dan dimanapun. Sedangkan lembar balik berdasarkan hasil uji coba dihasilkan angka diatas 90\% sehingga tergolong sangat layak sebagai media promosi kesehatan. (9)

Data capaian ASI Eksklusif yang didapatkan di 24 Kabupaten/Kota Provinsi Sulawesi Selatan, Kabupaten Bone adalah salah satu Kabupaten dengan angka pencapain ASI Eksklusif yang masih rendah dan justru mengalami penurunan tiap tahun serta masih jauh dari target pencapaian ASI Eksklusif yang telah ditetapkan oleh provinsi yaitu $87 \%$, pencapaian ASI Eksklusif di Kabupaten Bone dari tahun 2016-2018 selalu berada diangka 68\%. Data dari Dinas Kesehatan Kabupaten bone dari 38 puskemas, tahun 2016 jumlah bayi usia 0-6 bulan sebanyak 4.155 orang dan yang diberi ASI Eksklusif sebanyak $2.855 \quad(68,71 \%)$. Tahun 2017 jumlah bayi usia 0-6 bulan sebanyak 4.334 orang dan yang diberi
ASI Eksklusif sebanyak 2.968 (68,48\%). Pada tahun 2018 jumlah bayi 13.419 orang, bayi yang diberikan ASI Eksklusif sebanyak $(68,32 \%)$. (10)

Informasi dari kordinator KIA Puskemas Koppe didapatkan rendahnya cakupan ASI Eksklusif disebabkan karena masih banyak ibu yang memilih memberikan PASI ( Pengganti ASI) berupa susu formula dari pada memberikan ASI. Rendahnya cakupan ASI Ekslusif di wilayah kerja Puskesmas Koppe juga disebabkan karena akses informasi maupun sosialisasi tentang menyusui belum maksimal dilakukan. Berdasarkan wawancara awal yang dilakukan pada 12 ibu menyusui yang memiliki bayi usia 0-6 bulan di wilayah kerja Puskesmas Koppe didapatkan informasi bahwa mereka jarang menerima edukasi terkait ASI Eksklusif, edukasi hanya diberikan pada saat melakukan pemeriksaan kehamilan dan pada saat kegiatan posyandu akan tetapi edukasi yang diberikan hanya penyampaian informasi tanpa menggunakan media sehingga sulit dipahami oleh beberapa ibu menyusui.

Data yang didapatkan dari Dinas Kesehatan Kabupaten Bone dari 38 Puskesmas, salah satu puskesmas yang angka pencapaian ASI Eksklusifnya masih rendah adalah Puskemas Koppe. Data dari Puskesmas Koppe persentase 
bayi usia kurang dari 6 bulan mendapat ASI Eksklusif tahun 2017 jumlah bayi usia 0-6 bulan sebanyak 231 orang dan yang diberikan ASI Eksklusif sebanyak 103 (56,9\%) dan yang tidak diberikan ASI Eksklusif sebanyak 78 (43,1\%). Tahun 2018 jumlah bayi usia 0-6 bulan sebanyak 218 orang dan yang diberikan ASI Eksklusif sebanyak 135 (61,9\%) dan yang tidak diberikan ASI Eksklusif sebanyak $83(38,1 \%)$. Pada tahun 2019 jumlah bayi usia 0-6 bulan sebanyak 238 orang dan yang diberikan ASI Eksklusif sebanyak $162(68,1 \%)$ dan yang tidak diberikan ASI Eksklusif sebanyak 76 (31,9\%). (Profil Puskesmas Koppe Kab.Bone, 2019)

Berdasarkan uraian sebelumnya maka penulis merasa tertarik untuk melakukan penelitian tentang "Perbedaan Pengaruh Media Lembar Balik dan Kartu Kendali Edukasi Terhadap Pengetahuan dan Sikap Ibu Menyusui Tentang ASi Eksklusif di Wilayah Kerja Puskesmas Koppe Kabupaten Bone

\section{METODE}

Jenis penelitian ini adalah quasi eksperiment dengan pendekatan two- group pretest-posttest design. Populasi dalam penelitian ini adalah seluruh ibu menyusui yang memiliki anak usia 0-6 bulan yang ada diwilayah kerja puskemas Koppe sebanyak 215 ibu menyusui. Dengan menggunakan metode purposive sampling maka di peroleh sampel sebanyak 70 orang ibu menyusui. Penelitian ini dilakukan dalam beberapa tahap. Tahap I Melakukan pendataan ibu menyusui yang memiliki bayi 0-6 bulan sebagai sampel penelitian. Tahap II Data primer dikumpulkan untuk menilai pengetahuan dan sikap ibu tentang ASI Eksklusif diperoleh dengan menggunakan kuesioner. Tahap III merupakan yang diakukan yaitu berupa pemberian informasi melalui media lembar balik dan kartu kendali edukasi tentang ASI Eksklusif. Tahap IV yaitu 1 minggu setelah dilakukan intervensi maka pengukuran kembali pengetahuan dan sikap ibu dengan menggunakan kuesioner yang sama pada saat sebelum intervensi.

HASIL

Table 1. Distribusi Responden Berdasarkan Karakteristik Ibu Menyusui di Wilayah Kerja Puskesmas Koppe Kabupate Bone 


\section{Karasteristik}

n(35)

$\%$

\section{Umur}

$17-25$

11

31,4

26-35

17

36-45

Pendidikan

7

N

48,6

Tamat SD

Tamat SMP

15

20,0

Tamat SMA

4

$\%$

Tamat S1

Pekerjaan

Bekerja

Tidak Bekerja

Jumlah Anak

Anak pertama

$10 \quad 28,6$

42,9
11,4

$6 \quad 17,1$

N $\%$

Anak kedua

2

5,7

33

$\mathbf{N}$

94,3

11

$\%$

14

31,5

Anak ketiga

6

40,0

Diatas anak ketiga

4

17,1

11,4

Sumber : Data Primer 2020

Kelompok umur pada tabel 1 menunjukkan bahwa rata-rata usia ibu menyusui berusia antara 26-35 (48,6\%) dan paling banyak menamatkan pendidikannya SD $(42,9 \%)$. Sebagian besar ibu menyusui tidak bekerja $(94,3 \%)$ terlihat juga bahwa paling banyak ibu dengan jumlah anak pertama $(31,5 \%)$ dan anak kedua $(40,0 \%)$.

Tabel 2. Ditsribusi Frekuensi Berdasarkan Pengetahuan Ibu Menyusui Sebelum dan Sesudah Diberikan Intervensi di Wilayah Kerja Puskemas Koppe Kabupaten Bone

\begin{tabular}{ccccc}
\hline \multirow{2}{*}{ Tingkat Pengetahuan } & \multicolumn{2}{c}{ Pre test } & \multicolumn{2}{c}{ Post test } \\
\cline { 2 - 5 } & $\mathbf{n : 3 5}$ & \% & n:35 & \% \\
\hline Cukup & 9 & 25,7 & 29 & 82,9 \\
Kurang & 26 & 74,3 & 6 & 17,1 \\
\hline
\end{tabular}

Sumber : Data Primer 2020

Tabel 2. Menunjukkan bahwa ratarata pengetahuan ibu menyusui sebelum diberikan intervensi kurang, pengetahuan cukup hanya 9 ibu $(25,7 \%)$. Setelah diberikan intervensi pengetahuan ibu meningkat yaitu pengetahuan cukup sebanyak $29 \mathrm{ibu}(82,9 \%)$ dan pengetahuan kurang hanya 6 ibu $(17,1 \%)$. 
Tabel 3. Pengaruh Media Lembar Balik Terhadap Pengetahuan Ibu Menyusui Tentang ASI Eksklusif di Wilayah Kerja Puskemas Koppe Kabupaten Bone

\begin{tabular}{cccc}
\hline Variabel & Mean & Standar Deviasi & $\begin{array}{c}\text { Nilai } \\
\mathbf{p}\end{array}$ \\
\hline Pengetahuan & & & \\
Pre test & 8.20 & 2.53 & 0.000 \\
Post Test & 11.63 & 2.51 & \\
\hline
\end{tabular}

Sumber : Data Primer 2020

Tabel 3. menunjukkan bahwa nilai mean

untuk pengetahuan ibu menyusui tentang

ASI Ekslusif sebelum diberikan intervensi

menggunakan lembar balik memiliki nilai

8.20 , sedangkan nilai mean pengetahuan

ibu menyusui setelah intervensi dengan

nilai 11.63 , menunjukkan adanya

peningkatan nilai pengetahuan sebelum

dan sesudah intervensi. Hasil uji

menggunakan $T$ paired test diperoleh nilai

signifikansi adalah $\mathrm{p}$ value 0,000 ( $\mathrm{p}$ value

$<0,05)$ sehingga dapat disimpulkan ada

pengaruh media lembar balik terhadap

pengetahuan ibu menyusui tentang ASI

Eksklusif.

\section{DISKUSI}

Pengaruh media lembar balik terhadap pengetahuan ibu tentang ASI Eksklusif di Wilayah Kerja Puskesmas Koppe Kabupaten Bone

Hasil penelitian didapatkan pengetahuan ibu menyusui sebelum dilakukan intervensi menggunakan lembar balik berada pada kategori pengetahuan kurang yaitu sebanyak 26 orang $(74,3 \%)$ dan pengetahuan cukup hanya 9 orang $(25,7 \%)$, hal ini disebabkan penggunaan media lembar balik belum tersosialisasikan dengan baik dan informasi yang didapatkan ibu terkait IMD, ASI Eksklusif dan pemberian makanan pendamping ASI masih salah. Informasi hanya didapatkan saat persalinan, pemeriksaan kehamilan, dan saat kegiatan posyandu. beberapa ibu menjawab benar pengertian dari kolostrum, usia berapa sebaiknya bayi diberikan makanan pendamping ASI karena pernah membaca informasi tersebut di buku KIA. Kondisi lingkungan yang agak sulit dijangkau oleh petugas kesehatan menjadi kendala pemberian intervensi terutama di posyandu bulu 
dalam karena akses jalan yang kurang baik dan akses informasi yang sulit karena jaringan. Selain itu, karena beberapa pretest dilakukan saat posyandu dan ibuibu membawa anak mereka sehingga membuat ibu terkadang terksesan terburuburu menjawab pertanyaan dan sering tidak fokus.

Pemberian intervensi hari pertama menggunakan lembar balik dilakukan pada pagi dan siang hari di dua Posyandu yaitu Posyandu Bulu Luar dan Bulu Dalam Desa Bulu Allaporeng Kecamatan bengo, dengan dibantu oleh beberapa kader dan bidan desa untuk mengarahkan ibu menyusui yang memiliki anak usia 0-6 bulan sebelum dilakukan imunisasi untuk diberikan edukasi atau terkait ASI Eksklusif. Pemberian edukasi berjalan lancar karena kader menyiapkan ruangan khusus edukasi agar ibu menyusui tidak merasa terganggu dengan ibu-ibu yang lain dan hanya dibatasi sampai 5 orang dalam 1 kelompok. Akan tetapi kendala lain yang dialami adalah ibu-ibu membawa anak mereka untuk imunisasi sehingga kadang mengganggu konsentrasi saat pemberian edukasi jika ada anak bayi yang menangis. Pemberian intervensi berlangsung kurang lebih 15 menit dan selanjutnya ibu-ibu diberikan kesempatan untuk bertanya jika ada yang kurang dimengerti.
Perubahan pengetahuan ibu menyusui setelah diberikan intervensi menggunakan lembar balik dikarenakan ibu menyusui sudah sampai pada tahap tahu (know) yaitu ibu sudah dapat mengingat materi yang sudah diberikan seperti manfaat IMD dan ASI Ekslusif bagi bayi, pengertian ASI Eksklusif, kapan bayi harus diberikan makanan pendamping ASI, ibu sudah sampai pada tahap memahami (comprehension) hal ini terlihat dari kemampuan ibu untuk menjelaskan secara benar tentang materi yang diketahui dan menginterpretasikan materi secara benar seperti tata cara melakukan IMD, jenisjenis ASI dan ibu sudah dapat memahami batas usia pemberian.

Kelebihan dari media lembar balik adalah gambar yang jelas dan dapat dilihat secara bersama-sama, menarik dan mudah di mengerti. 6 ibu yang memiliki pengetahuan kurang setelah diberikan edukasi tetap menunjukkan peningkatan pengetahuan dan tidak ada ibu yang memiliki pengetahuan tetap sebelum dan sesudah diberikan edukasi meskipun tidak berada pada kategori cukup, hal ini disebabakan karena ingatan berkurang dan penerimaan yang kurang fokus.

Hasil penelitian (Masthura et al., 2020) tentang Efektivitas lembar balik dan leaflet terhadap pengetahuan ibu hamil tentang pemberian makanan 
pendamping ASI (MP-ASI) di wilayah kerja Puskesmas Baiturrahman Kota Banda Aceh, menunjukkan adanya peningkatan nilai pengetahuan sebelum dan sesudah konseling menggunakan lembar balik. Hasil uji statistic diperoleh nilai signifikansi adalah 0,002 sehingga dapat disimpulkan ada perbedaan antara nilai pre test dan post test pengetahuan ibu hamil tentang Makanan Pendamping ASI. Persamaan penelitian ini dengan penelitian terdahulu yaitu sasaran penelitian usia 20-35. Perbedaan penelitian ini dengan penelitian terdahulu yaitu sasaran penelitian ini adalah ibu menyusui yang memiliki bayi usia 0-6 bulan dan penelitian terdahulu sasarannya adalah ibu hamil. (11)

Saat pretest dari 14 ibu menyusui yang pendidikan terakhir SD 2 diantaranya memiliki pengetahuan cukup sedangkan 6 ibu yang Pendidikan terakhir D3 dan S1, 3 diantaranya memiliki pengetahuan kurang tentang ASI Eksklusif. Jumlah anak harusnya bisa membuat ibu lebih berpengalaman dan tahu terkait ASI Eksklsuif karena ibu sudah mendaptkan edukasi berulang terkait IMD dan ASI Eksklusif pada saat kehamilan dan melahirkan, dari 9 ibu yang memiliki pengetahuan cukup saat pretest sebanyak 6 ibu yang memiliki anak pertama justru memiliki pengetahuan cukup dan 22 ibu menyusui memiliki anak
2,3,4 dan 5 pengetahuan tentang ASI Eksklusif kurang. Berdasarkan informasi dari ibu menyusi hal ini disebakan karena pengetahuan ibu dan cara melakukan IMD yang salah pada saat melahirkan, sedangkan IMD adalah salah satu kunci suksesnya ASI Eksklusif dan masih banyak ibu yang memberikan susu formula kepada bayi dengan alasan produksi ASI kurang. Faktor pemungkin penting yang menyebabkan terjadinya kegagalan dalam pemberian ASI adalah ibu tidak difasilitasi untuk melakukan IMD (Fikawati \& Syafiq, 2009). Bayi yang lahir normal dan diletakkan di perut ibu segera setelah lahir dengan kulit ibu melekat pada kulit bayi selama setidaknya 1 jam dalam 50 menit akan berhasil menyusu, sedangkan bayi lahir normal yang dipisahkan dari ibunya 50\% tidak bisa menyusu sendiri. (12)

Berdasarkan analisa peneliti, peningkatan pengetahuan ibu tentang ASI Eksklusif setelah diberikan intervensi menggunakan lembar balik tidak lepas dari antusias atau rasa ingin tahu dari ibu yang sangat tinggi. Media yang tepat dan kemasan yang menarik dalam penyampaian pesan sangat mempengaruhi tingkat keberhasilan penyampaian makna dari pesan tersebut. Meskipun demikian, masih ada beberapa ibu yang tidak menunjukkan peningkatan pengetahuan ke kategori cukup. Hal tersebut karena 
ada faktor-faktor lain yang mempengaruhi sehingga peningkatan pengetahuan ibu tidak tercapai $100 \%$, seperti ingatan berkurang dan penerimaan yang kurang fokus juga menjadi masalah, kedua faktor pelayanan kesehatan mutu pelayanan yang kurang professional, serta kondisi lingkungan yang tidak mendukung.

\section{KESIMPULAN}

Terdapat pengaruh signifikan peningkatan pengetahuan sebelum dan sesudah diberikan intervensi dengan media lembar balik dengan nilai $\mathrm{p}$ value 0,000 ( $\mathrm{p}$ value $<0,05)$. Kelebihan lembar balik adalah gambar yang jelas dan dapat dilihat secara bersama-sama, menarik dan mudah di mengerti sehingga dapat meningkatkan pengetahuan ibu menyusui tentang ASI Eksklusif. Edukasi laktasi perlu juga diberikan pada orang tua dan suami serta perlu tindak lanjut berupa home care pada ibu menyusui untuk memantau masalah IMD dan ASI Eksklusif terutama dalam satu minggu pertama melahirkan

\section{DAFTAR PUSTAKA}

1. Kemenkes RI. (2018). Pedoman Pekan Asi Sedunia (PAS) Tahun 2018. Direktorat Gizi Masyarakat.

2. Notoatmodjo, S. 2014. (2015). Ilmu Perilaku Kesehatan. Jakarta: Rineka Cipta. Biomass Chem Eng.
3. Prasetio, T. S., Permana, O. R., \& Sutisna, A. (2020). Hubungan Pengetahuan, Sikap, dan Perilaku Ibu Tentang ASI dengan Keberhasilan ASI Eksklusif: Puskesmas Pancalang Kabupaten Kuningan. Jurnal Kedokteran \& Kesehatan Hubungan, 6(1), 1-6.

4. Notoatmodjo, Soekidjo. (2012). Promosi Kesehatan \& Ilmu Perilaku. Jakarta: Rineka Cipta.

5. Muldaniyah, M., Ahmad, M., \& Hadju, V. (2019). Efek Kartu Kendali Edukasi Inisiasi Menyusu Dini pada Ibu Hamil Trimester III. Jurnal Ners Dan Kebidanan (Journal of Ners and Midwifery), 6(2), 147-155. https://doi.org/10.26699/jnk.v6i2.art.p $\underline{147-155}$

6. Riskesdas. (2018). Hasil Utama Riset Kesehatan Dasar. Kementrian Kesehatan Republik Indonesia, 1-100

7. Selatan, D. K. P. S. (2018). Profile Kesehatan Provinsi Sulawesi Selatan. Journal of Chemical Information and Modeling, 53(9), 1689-1699.

8. Notoatmodjo, Soekidjo. (2012). Promosi Kesehatan \& Ilmu Perilaku. Jakarta: Rineka Cipta.

9. Surya Wibowo, D. S. (2011). Metodologi Penelitian Kuantitatif Kualitatif dan R \& D, Cetakan kedelapan, Penerbit Alfabeta, Bandung., 7(2), 67-74. 
10. Profil Dinas Kesehatan Kabupaten Bone 2018. (n.d.). Retrieved from https://www.bkpsdm.bone.go.id/2018/ 04/16/dinas-kesehatan/

11. Masthura, R., Yuniwati, C., \& Ramli, N. (2020). Efektivitas lembar balik dan leaflet terhadap pengetahuan ibu hamil tentang pemberian makanan pendamping ASI (MP-ASI). Jurnal SAGO Gizi Dan Kesehatan, 1(1), 9. https://doi.org/10.30867/gikes.v1i1.28 $\underline{3}$

12. Idris, F. P., \& Gobel, F. A. (2019). Efektivitas Media Audio Visual dalam Peningkatan Perilaku Inisiasi Menyusu Dini (IMD) pada Ibu Hamil di Wilayah Kerja Tinggimoncong Tahun 2019. Prosiding Seminar 